\title{
Review of Polymers for Heat Exchanger Applications: Factors Concerning Thermal
}

\section{Conductivity}

\author{
Afrin Roja Jahir Hussain ${ }^{1}$, Abbas A. Alahyari ${ }^{2}$, Scott A. Eastman ${ }^{2}$, Catherine Thibaud-Erkey ${ }^{2}$, \\ Stephen Johnston ${ }^{1}$, Margaret J. Sobkowicz ${ }^{1 *}$ \\ ${ }^{1}$ Department of Plastics Engineering, University of Massachusetts Lowell \\ ${ }^{2}$ United Technologies Research Center \\ * Corresponding Author: margaret_sobkowiczkline@uml.edu, \\ University of Massachusetts Lowell, 1 University Ave, Lowell, MA 01854 USA
}

\begin{abstract}
Polymeric materials hold several advantages over metal components in heat exchangers such as cost savings, lighter weight and corrosion resistance. However, it is challenging to engineer plastics with good heat transfer characteristics, processability and required strength. Neat polymer resins have inferior mechanical and thermal properties relative to metals, requiring careful consideration of the entire heat exchanger system from materials to system design, to achieve sufficient performance. This review summarizes the physical parameters governing polymer and composite thermal conductivity, as well as the latest research on augmenting thermal conductivity. Highly filled composites containing carbon or metal have achieved thermal conductivity an order of magnitude higher than that of neat polymers. The effects of critical additive characteristics, such as interfacial compatibility, filler shape factor, loading level and processing technique, are reviewed. In addition to lower material costs, high volume processing technologies such as injection molding and extrusion are responsible for the cost savings of
\end{abstract}


polymers over metals. Thus, the manufacturing considerations for the most promising high thermal conductivity polymer composites are also reviewed.

Keywords: Thermally conductive polymers, plastic heat exchangers, functional composites

\section{INTRODUCTION}

Heat exchangers play a crucial role in a wide range of engineering systems, from building air handlers to automobiles to manufacturing plants. They require materials capable of transferring heat at high rates while also minimizing thermal expansion over the usage temperature range [1]. Conventionally, metals are used for applications where effective and efficient heat exchange is required, since many metals exhibit thermal conductivity over 100 $\mathrm{W} / \mathrm{mK}$. Although metals are currently the material of choice for heat transfer applications, polymer composites offer improvements regarding weight, corrosion and fouling and cost.

\subsection{Intrinsic thermal conductivity of polymers}

Replacing metals with thermoplastics for heat exchanger applications involves substantial challenges including low mechanical strength, high thermal expansion, physical and environmental aging, lower service temperature ranges and difficulty in joining. Mismatch in thermal expansion between thermoplastic and metallic components may pose an additional challenge at a system level. Most commodity thermoplastics in their virgin form exhibit thermal conductivity in the range of 0.1 to $0.3 \mathrm{~W} / \mathrm{mK}$, which is not ideal for heat exchanger applications 
when compared to $200 \mathrm{~W} / \mathrm{mK}$ to $300 \mathrm{~W} / \mathrm{mK}$ for metals such as aluminum or copper. Fundamentally, polymer thermal conductivity is driven by phonon transport: quantized vibrational modes that propagate through a material. Thermoplastics typically exhibit low atomic density, covalent chemical bond structures, structural inhomogeneity or defect density, and mismatch in molecular vibrations which are consequently the same characteristics that inhibit phonon transport; thus, thermal conductivity for thermoplastics is inherently low.

Another aspect to consider is the intrinsic thermal transport in the polymer matrix. Polymer crystallinity, chemical structure, bond strength, defects, presence of side chains, molecular weight, glass transition temperature, and melting temperature can potentially affect the thermal conductivity of pure thermoplastics. Crystalline thermoplastics have inherently higher thermal conductivity, as the higher density and ordered chain alignment improve phonon transport. On the other hand, amorphous thermoplastics exhibit small mean free path due to phonon scattering [2]. Melt temperature and glass transition temperature influence the temperature-dependence of the thermal conductivity in case of crystalline and amorphous thermoplastics, respectively [3]. As temperature increases above $\mathrm{T}_{\mathrm{g}}$ in crystalline thermoplastics, thermal conductivity decreases due to thermal expansion; however, amorphous thermoplastics show a monotonic increase in thermal conductivity with increasing temperature due to more molecular mobility [4-7]. Orientation of polymer chains results in increased thermal conductivity along the aligned direction relative to that in the orthogonal directions [4,5]. Aligned polymer molecules increase thermal conductivity and can be achieved during processes such as drawing and extrusion [6]. Some specific structures such as phenylene in the polymer backbone, which provides a percolation path, or polymer blends with thermal intermolecular interactions (e.g., hydrogen bonds rather than weak van der Waals forces) could improve thermal 
conductivity [3,7]. Although the effect on thermal conductivity is subtle, crosslinking yields stronger adhesion between molecules and conductive pathways are created for heat transfer through the matrix. Side chains may increase phonon scattering and reduce axial conductivity [8]. Shen et al [9] reported that the thermal conductivity of a single polyethylene nanofiber was close to $100 \mathrm{~W} / \mathrm{mK}$ when compared to $0.33 \mathrm{~W} / \mathrm{mK}$ for bulk low density polyethylene, demonstrating that it is possible to alter the molecular structure or the morphology to modify the intrinsic thermal transport of polymer molecular assemblies.

Development in materials science and engineering has paved the way to overcome the typical complications associated with using thermoplastics in heat exchangers. Adding suitable fillers that possess high thermal conductivity can increase the overall thermal conductivity of the composite by forming a percolating network for thermal transport [10]. These fillers could be metals, carbon, ceramics or a mixture of all of the above. Inclusion of fillers, depending on the amount, shape and type can greatly affect mechanical performance and can interfere with processability due to high viscosity and increased thermal conductivity of the composite. Typically, the thermal conductivity estimated from a rule of mixtures calculation grossly overvalues the thermal conductivity of the composite. While adding filler can improve thermal conductivity, new interfaces, imperfections, impurities and flaws are also introduced into the composite system that increase phonon scattering and effectively slow down thermal transport from the estimated theoretical upper limit. The next section will summarize the various salient parameters in polymer composites designed for improved heat transfer.

\subsection{Influence of composite properties}


Factors dominating composite properties include filler surface treatment and interfacial structure, filler aspect ratio, alignment and packing structure, filler volume fraction, particle size, shape, purity, polydispersity and intrinsic conductivity. Usage temperature, mechanical loading and processing parameters can also influence thermal conductivity in finished devices. Several commercial thermoplastic resins compounded with conductive fillers are available with reported thermal conductivity values up to $35 \mathrm{~W} / \mathrm{mK}$ (e.g., Celanese CoolPoly LCP-based grades); however, optimal heat exchanger design and manufacturing must also be considered in selection of the ideal material.

In general, composite thermal conductivity increases with filler content and decreases with particle size. Polydisperse filler yields higher thermal conductivity than that obtained with monodispersed filler [11]. Hybrid composites with fillers of different shapes and sizes incorporate properties of all fillers and form better conductive pathways [14]. Composite processing presents problems such as achieving proper dispersion and forming continuous conductive paths throughout the matrix. Interfacial flaws such as voids or air gaps increase thermal resistance $[6,12]$ due to increased phonon scattering $[12,13]$. In theory, when a thermally conductive pathway is achieved, reduced phonon scattering at the interface results in thermal conductivity close to that of the filler alone, with the polymer serving as the structural binder. Fillers on the nanoscale tend to aggregate, reducing the effective surface area-to-volume ratio and aspect ratio. This results in a larger critical weight loading to achieve percolation within the composite. To overcome these problems, several processing strategies have been adopted such as solution dispersion, high shear extrusion and filler functionalization to increase compatibility with the polymer matrix. 
Molding processes such as extrusion and injection will cause the fillers to align along the direction of flow. This creates anisotropy in the case of one-dimensional and two-dimensional fillers and would lead to varied properties in orthogonal directions, i.e., lower thermal conductivity normal to the flow direction. Isotropic fillers produce composites that exhibit similar properties in all directions. Furthermore, thermal expansion can have the effect of disrupting the thermal network. Processing can also have critical impact on the final product properties due to excessive temperature and shear, which can degrade the polymer matrix.

In summary, filler material, shape, surface chemistry and loading level all affect composite thermal conductivity. Careful selection of thermoplastic and filler properties can lead to significant thermal conductivity improvements for thermoplastic heat exchanger applications.

\section{PLASTIC HEAT EXCHANGER DESIGN}

As discussed previously, polymers are typically not thought of as the intuitive material choice for applications where thermal transport is required due to their low thermal conductivity. However, the distinct advantages that polymeric materials possess can be exploited to compete with metallic heat exchangers from a system performance standpoint. Low temperature processing, shaping and joining, antifouling, and anticorrosion are among the primary performance advantages. In order to achieve the thermal transport performance that is attained in conventional metal heat exchangers, substantial redesign is necessary. For low thermal conductivity materials, prime surface HX designs are more appropriate than the extended surface HX designs. . In addition, through careful selection of the thermally conductive polymer composite and understanding of the interplay of thermal conductivity, processability, and mechanical strength, it is possible to optimize the polymeric material and the heat exchanger 
design concurrently. Several typical heat exchangers designs are discussed below vis a vis polymeric versions of the conventional metal designs.

Plate heat exchangers (Figure 1) are one exemplary design where stacked plates are joined. A chevron pattern is incorporated on each plate to increase the overall surface area and promote turbulent flow for enhanced heat transfer. This simplified design is ideal from a polymer processing standpoint as the geometry of plate elements of this system can be easily extruded or injection molded with standard polymer resins. Due to the reduced strength of polymers compared to metals and the conventionally very thin metal plates, this geometry must be substantially redesigned. Despite these challenges, several groups have been able to make different variations of the polymeric plate heat exchangers. One example is a cross flow heat exchanger produced using polyvinylidene fluoride (PVDF) or polypropylene (PP), consisting of plates and channels [15]. Another plate and fin heat exchanger was made with corrugated sheets separated with flat plates, resulting in relatively higher surface area. In this example, a finned tube plastic heat exchanger was developed using polypropylene with higher thermal conductivity $(16.5 \mathrm{~W} / \mathrm{mK})$, and overall heat transfer coefficient of $34 \mathrm{~W} / \mathrm{m}^{2} \mathrm{~K}$ was achieved. The presence of fins also provided improved mass transfer area [16]. 


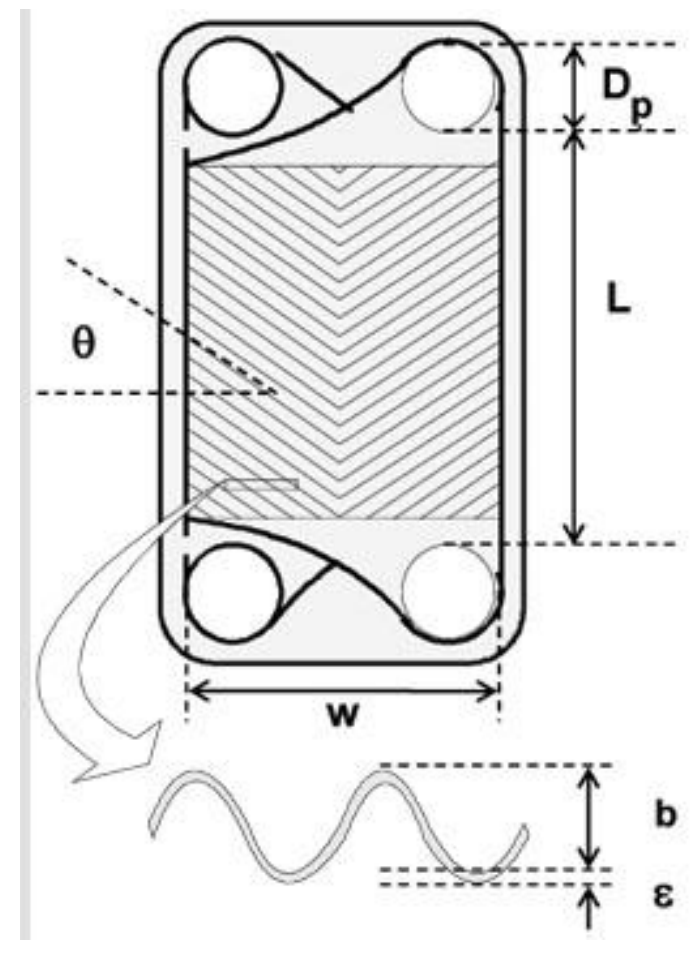

Figure 1 Representative diagram of a plate from a plate-and-frame heat exchanger.[17]

Another common heat exchanger design is the shell and tube (Figure 2), which exchanges heat between fluid flowing within the tubes and fluid flowing around the exterior of the tubes. Critical parameters are wall thickness of the tubes, interfacial resistances between the fluids and the walls of the tube, and fluid flow rates. System efficiency can be enhanced by employing surface topology modification to provide more contact area and turbulent flow. This design is also fairly conducive to manufacturing using conventional polymer processing. Tubes can be extruded to the desired inner diameter, outer diameter, and length and the shell can be fabricated using a number of different strategies. For polymers, this design has several advantages over the plate type heat exchanger. The strength of the material is less of a factor as tubes can be designed to withstand a given pressure by adjusting the wall thickness and diameter of the tube. This can enable very thin-walled tubes, which is critical to sufficient performance. Several 
groups have demonstrated thin walled polymeric shell and tube heat exchangers with performance comparable to metal counterparts [18]. One example of a PVC shell and tube heat exchanger made by Morcos and Shafey [19] with reduced wall thickness and conical PVC turbulators increased the heat transfer by a factor of 3.5. Liu et al. [20] created a polymer shell and tube heat exchanger with thicker cross linked polyethylene tubes $(1.78 \mathrm{~mm})$ and thinner nylon tubes $(0.2 \mathrm{~mm})$ with a thermal conductivity of 0.38 and $0.31 \mathrm{~W} / \mathrm{mK}$, respectively. They found that the thinner nylon tubes could be reduced in length by $75 \%$ compared to the cross linked polyethylene tubes to obtain the same results, due to lower thermal resistance of thinner nylon tubes.

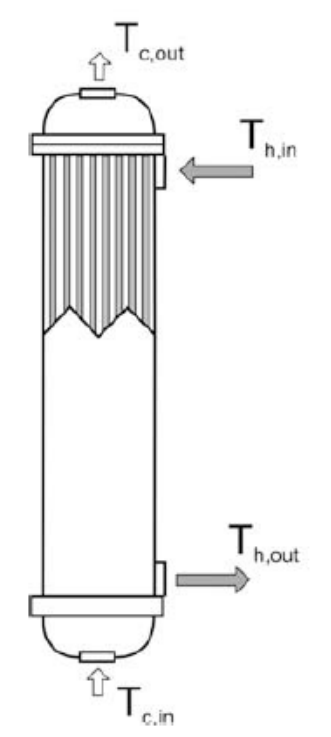

Figure 2. Shell and tube heat exchanger [20]

Novel polymer heat exchanger designs have been demonstrated. as in Kundalwal et al. [21], which describes a fuzzy carbon fiber heat exchanger using wavy carbon nanotubes over the surface of hollow cylindrical carbon fiber embedded on carbon nanotube reinforced polymer matrix. This polymeric hollow fiber construction (Figure 3) has extremely large surface area and 
higher efficiency than metal heat exchangers. Hollow capillary fibers are potted at the ends with adhesives such as epoxy, and the bundle of tubes forms the heat exchange medium. The heat transfer rate depends on fiber length, diameter, and material composition. Qin et al. [22] produced hollow fibers by melt mixing polypropylene and 15\% graphite and obtained overall heat transfer coefficient of $1228.7 \mathrm{~W} / \mathrm{m}^{2} \mathrm{~K}$, five times higher than that of pure PP hollow fibers. Yan et al. [23] improved the heat transfer rate of carbon hollow fiber heat exchangers, optimizing their structure by placing graphite-filled polypropylene between the inlet and outlet of the shell side. Heat transfer coefficient with the carbon network $\left(1573-2627 \mathrm{~W} / \mathrm{m}^{2} \mathrm{~K}\right)$ was double that of heat exchangers without the graphite $\left(757-1172 \mathrm{~W} / \mathrm{m}^{2} \mathrm{~K}\right)$. While the heat transfer coefficients of these types of heat exchangers are impressive, scale up and cost of these systems is a substantial challenge that must be addressed to make these designs viable for wide scale use.
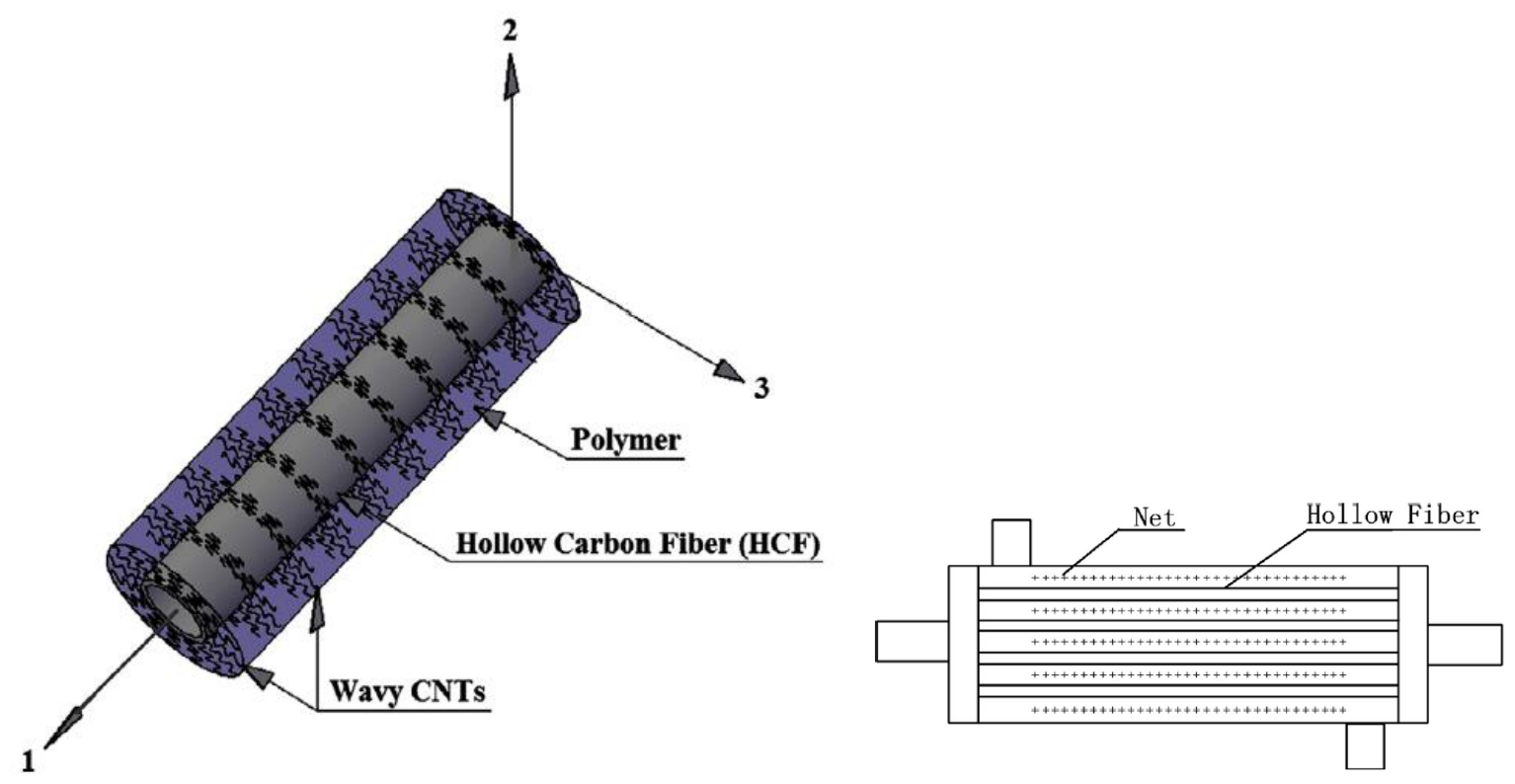

Figure 3. Polymeric hollow fiber heat exchangers [21] 
While this list is not exhaustive, the examples presented here demonstrate a common theme. It is not enough to attempt to replace metal with polymer in a design that is optimized for a metallic material. For polymeric heat exchangers to compare to conventional metallic heat exchangers, it is critical to leverage the strengths associated with polymeric materials and consider heat exchanger designs that are enabled by the material. Minimizing wall thickness, increasing surface area, incorporating hairy fibers, additives, and surface topology are some of the strategies that are either unique or easier to achieve through the use of polymeric materials.

\section{CANDIDATE FILLERS}

Heat exchangers as conventionally conceived require thermal conductivity values of at least $10 \mathrm{~W} / \mathrm{mK}$ [24]. To achieve this in polymers fillers are added; some enhance the heat transfer quality of composites, while others are detrimental to the overall composite properties. [25,26] High loading makes the plastics difficult to process and nanoscale fillers tend to aggregate. Addition of too much filler can also create processing issues due to increased viscosity, friction and wear properties. The three classes of filler, metals, ceramics and carbon, are reviewed below.

\subsection{Metal based fillers}

Metallic fillers such as aluminum, silver, copper, etc. can impart both thermal and electrical conductivity to composites. Table 1 shows representative thermal conductivity, coefficient of thermal expansion and density of a few metal fillers. Typically, metallic fillers are available in different dimensionalities: 3D isotropic (spherical or cubic), 2D platelets or flakes, and 1D rods or fibers. Shape and spatial distribution of the filler particles control the electrical 
and thermal properties of metal filled polymer systems [27]. Metallic fillers with smaller particle size impart higher thermal conductivity [28]. Mechanical properties such as modulus and stress at break typically increase when polymers are filled with metallic inclusions. Problems such as increase in density, oxidization and corrosion are often encountered; treatments that prevent corrosion and surface oxidation are required. Also, high filler content leads to abrasion of processing equipment.

Table 1: Thermal conductivity of metallic fillers [29,30]

\begin{tabular}{llll}
\hline Material & $\mathbf{K}(\mathbf{W} / \mathbf{m K})$ & $\mathbf{C T E}\left(\mathbf{1 0}^{-\mathbf{6}} \mathbf{C}\right)$ & $\begin{array}{l}\text { Density } \\
\left(\mathbf{g} / \mathbf{c m}^{\mathbf{3}}\right)\end{array}$ \\
\hline Aluminum & 247 & 23 & 2.7 \\
Copper & 483 & 17 & 8.9 \\
Nickel & 158 & 13 & 8.9 \\
Silver & 450 & 18 & 10.49 \\
\hline
\end{tabular}

In one example incorporation of nickel powder into high-density polyethylene resulted in mechanically strong composites with electrical conductivity of $8.3 \times 10^{3} \mathrm{~S} / \mathrm{m}$ and thermal conductivity of $1.99 \mathrm{~W} / \mathrm{mK}$ at $30 \mathrm{vol} \%$. [31] Note that this value is far lower than that obtained from a simple mixing rule; this illustrates the challenges in obtaining ideal structures in the composite. Boudenne et al. [28] incorporated copper particles in polypropylene $(\mathrm{k}=0.24 \mathrm{~W} / \mathrm{mK})$ matrix and obtained a thermal conductivity of $2.45 \mathrm{~W} / \mathrm{mK}$ at $45 \mathrm{vol} \%$ loading. Rusu et al. [32] studied the effect of mechanical and thermal properties of zinc powder filled high density 
polyethylene composites. Vicat softening point was increased with zinc powder content and thermal conductivity of $1.7 \mathrm{~W} / \mathrm{mK}$ was achieved at 20 vol\%. Luyt, Molefi and Krump [33] found that $24 \mathrm{vol} \%$ copper content in the thermoplastics increased thermal conductivity of polyethylene by a factor of two

\subsection{Carbon based fillers}

Carbon based fillers include carbon black, carbon fiber, graphite, graphene, single-wall and multiwall carbon nanotubes and nanosheets, all of which increase both thermal and electrical conductivity and mechanical properties of the composites [34,35]. Table 2 contains typical thermal conductivity ranges of carbonaceous fillers. The carbon fillers have relatively low bulk density in contrast to metallic fillers. They are found to be inert and compatible with thermoplastics. Conductivity depends on the regularity of the $\pi$-bonding structure and the freedom from defects. Graphene has the highest thermal conductivity, making it an excellent choice for heat transfer [36]. Single-walled and multi-walled carbon nanotubes have high inherent thermal conductivity; however, they are very expensive and difficult to disperse in a matrix. Carbon structures also have low coefficient of thermal expansion, and are resistant to corrosion and chemical decomposition [37]. Fibers show excellent properties along the long axis; however, properties are reported to be much lower along the transverse direction.

Table 2: Thermal conductivity of carbon based fillers [38,39]

\begin{tabular}{ll}
\hline Material & K (W/mK) \\
\hline Carbon black & $6 \sim 174$ \\
Carbon fiber (PAN) & $8 \sim 70$ \\
\hline
\end{tabular}




\begin{tabular}{ll}
\hline Carbon fiber (Pitch) & $530 \sim 1100$ (axis) \\
Carbon nanotubes & $2000 \sim 6000$ (axis) \\
Graphite & $100 \sim 400$ (on plane) \\
Graphene & $5000-6000$ \\
\hline
\end{tabular}

Carbon composites result in light weight thermoplastic composites possessing very high thermal conductivity. Chen and Ting [40] achieved $695 \mathrm{~W} / \mathrm{mK}$ and density less than $1.5 \mathrm{~g} / \mathrm{cm}^{3}$ by fabricating 56 vol\% vapor grown carbon fiber -reinforced epoxy composites. Ha et al. [41] studied the thermal conductivity of graphite filled-liquid crystal thermoplastic composites; filler content was varied from 0 to $70 \mathrm{wt} \%$. They found that addition of graphite significantly reduced thermal expansion. Thermal conductivity values were found to increase from 0.40 and 0.25 $\mathrm{W} / \mathrm{mK}$ to 28.3 and $13.9 \mathrm{~W} / \mathrm{mK}$ for in-plane and through-plane directions, respectively, which represents 71-fold and 56-fold increase, as shown in Figure 4.

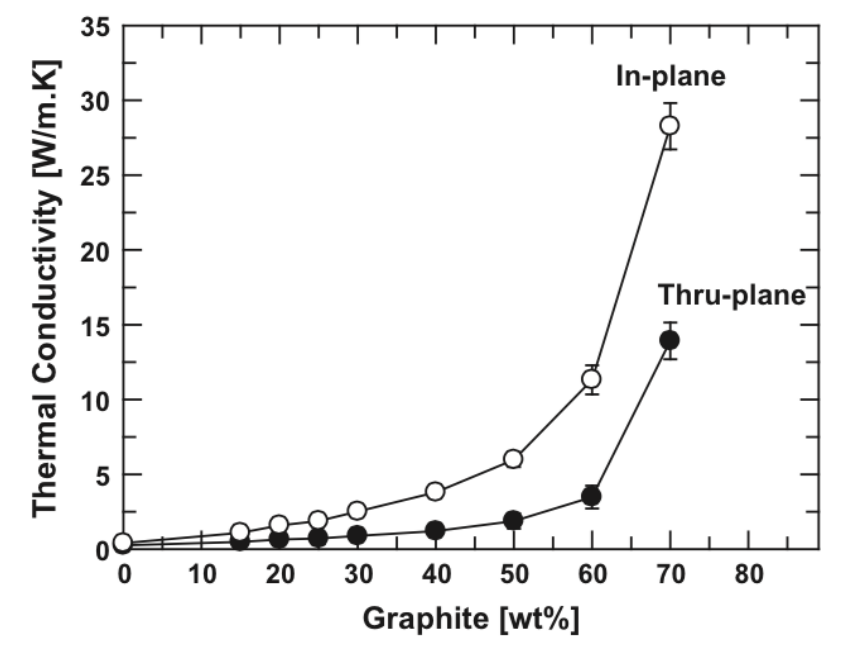

Figure 4. Effect of addition of graphite on thermal conductivity[42] 


\subsection{Ceramic based fillers}

Ceramic fillers such as aluminum nitride, boron nitride, silicon carbide, and beryllium oxide are used when the final product needs to be thermally conductive but electrically resistive and possess low coefficient of thermal expansion. Boron nitride and aluminum nitride have hexagonal planar structure similar to graphene which accounts for their high thermal conductivity. The atoms are connected via ionic and covalent bonds and this combination results in high thermal stability. Typical thermal conductivity ranges of ceramic fillers are shown in Table 3 [30].

Table 3. Thermal conductivity of ceramic based fillers [30]

\begin{tabular}{llll}
\hline Material & K $(\mathbf{W} / \mathbf{m K})$ & CTE $\left(\mathbf{1 0}^{-\mathbf{6}} / \mathbf{C}\right)$ & Density $\left(\mathbf{g} / \mathbf{c m}^{3}\right)$ \\
\hline Aluminum nitride & 320 & 4.5 & 3.3 \\
Beryllium oxide & 260 & 6 & 3 \\
Boron nitride & 320 & 2.9 & 2.10 \\
Silicon carbide & 270 & 3.7 & 3.3 \\
\hline
\end{tabular}

Thermoplastic composites with ceramic exhibit high thermal stability, lower shrinkage, and dimensional stability. They possess relatively lower density compared to metals and can endure very high service temperature ranges. Difficulties involved in preparation of ceramic fillers that are compatible with thermoplastics make them relatively more expensive than both metal and carbon fillers. 
, Leung et al. [43] achieved $800 \%$ improvement in thermal conductivity over neat polyphenylene sulfide by adding $33.3 \mathrm{vol} \%$ of hexagonal boron nitride spherical particles. Xu et al. [44] added aluminum nitride whiskers and particles to polyvinylidene fluoride, achieving 11.5 W/mK with60 vol\% and aluminum nitride whisker:particle ratio of 1:25.7. Ishida and Rimdusit [45] demonstrated $0.2 \mathrm{~W} / \mathrm{mK}$ at $30 \mathrm{vol} \%$ of filler content to $32.5 \mathrm{~W} / \mathrm{mK}$ at $78.5 \mathrm{vol} \%$ in boron nitride- polybenzoxazine composites, attributing the increase to the formation of conductive network. Yu, Hing and Hu [46] achieved $\sim 1 \mathrm{~W} / \mathrm{mK}$ at 40 vol\% aluminum nitride in polystyrene, , an $85 \%$ increase in thermal conductivity compared to $0.15 \mathrm{~W} / \mathrm{mK}$ without filler.

\subsection{Hybrid Composites}

Hybrid systems involve a combination of fillers resulting in a synergistic effect and a balance in final properties. For instance, glass spheres or fibers are added along with carbon to provide mechanical stability to the resin at higher loading levels.

Pak et al. [47] studied the synergistic improvement in thermal conductivity of polyphenylene sulfide composites with a combination of fillers and obtained highest thermal conductivity of about $1.74 \mathrm{~W} / \mathrm{mK}$ with $1 \mathrm{wt} \%$ multiwalled carbon nanotubes and $50 \mathrm{wt} \%$ boron nitride. Wang et al. [8] embedded highly crystalline fibers such as Vectra, Kevlar, and Zylon in epoxy matrix and achieved $19 \mathrm{~W} / \mathrm{mK}$ in case of Zylon AS and $23 \mathrm{~W} / \mathrm{mK}$ for Zylon HM. However, when temperature was increased, they found a drop in thermal conductivity values of the composites, which could be attributed to expansion of aligned molecules and deterioration in conductive paths. Zhu et al. [48] investigated LDPE matrix composites filled with hollow glass microspheres and nitride particles and obtained a thermal conductivity value of $1 \mathrm{~W} / \mathrm{mK}$ at 50 vol\%. Liang [49] found that the thermal conductivity of polypropylene/hollow glass bead 
composites decreased with increased filler content in the matrix, not unexpected since the hollow glass beads create low conductivity air voids in the matrix.

Cao et al. [50] studied the effects of localization of hybrid fillers including MWCNT and $\mathrm{SiC}$ in an immiscible blend of PVDF/PS in 30/70 ratio. Thermal conductivity increased to 1.85 $\mathrm{W} / \mathrm{mK}$ at $2.9 \mathrm{vol} \%$ of MWCNT and $11.4 \mathrm{vol} \% \mathrm{SiC}$ from $0.14 \mathrm{~W} / \mathrm{mK}$ for the unfilled blend. The increase was attributed to phase separation of the conductive fillers to the interfaces in the blend. Polyamide 6 fiber-reinforced composites with magnesium hydroxide, alumina and graphite flakes (Li et al. [51]) achieved $1.95 \mathrm{~W} / \mathrm{mK}$ (no fiber), $2.1 \mathrm{~W} / \mathrm{mK}$ (carbon fiber) and $1.88 \mathrm{~W} / \mathrm{mK}$ (glass fiber). Carbon fiber provided the composite with highest tensile properties, flexural properties and heat deflection temperature.

\section{FILLER FEATURES AND HANDLING}

This section deals with the various factors involved in the inclusion of fillers to thermoplastic resins for the improvement of heat transfer characteristics. Surface pretreatments, filler purification, and other modifications may be necessary to ensure proper adhesion of filler particles to the polymer resin. The amount of filler added and the filler aspect ratio are important parameters which determine the final thermal conductivity of the composite. Filler alignment can also affect thermal conductivity and depends on processing variables such as shear rate and temperature.

\subsection{Filler purification, surface treatment and modification}


Thermoplastics are hydrophobic and in some cases these materials may not bond well with the typically polar surfaces of metal, ceramic or carbon fillers. One strategy to mitigate effects of interfacial flaws and thermal contact resistance is to modify filler surfaces by purification, surface treatment or addition of functional groups. Improved wettability and dispersion of fillers reduces interfacial resistance, thereby increasing the thermal conductivity. Polymer chains can be grafted to filler particles, for example Kim et al. [52] grafted poly (Llactide) to multi-walled carbon nanotubes, increasing thermal conductivity of the composite from $0.15 \mathrm{~W} / \mathrm{mK}$ (neat PLLA) to $0.42 \mathrm{~W} / \mathrm{mK}$.

Silane chemistry is a widely used and versatile modification scheme for hydroxyl-bearing surfaces. Some silane moieties can react with the polymer as well as the filler, creating siloxane bridges for strong and stable interfaces. Ahn et al. [53] surface treated boron nitride with polysilazane, fabricated a composite with nylon 6,6 matrix and observed increase in thermal conductivity from 0.37 to $0.42 \mathrm{~W} / \mathrm{mK}$ through-plane and 4 to $4.9 \mathrm{~W} / \mathrm{mK}$ in-plane after the surface treatment. The Muratov group [54] and demonstrated an increase from 0.256 to 0.369 $\mathrm{W} / \mathrm{mK}$ in hexagonal boron nitride - polypropylene composites resulting from a silane surface treatment. Lee et al. used titanate couplers (KR 138S) to achieve an $86 \%$ increase in thermal conductivity, which was attributed to good wetting between aluminum nitride and high density polyethylene matrix [55]. Cao et al. achieved better dispersion of filler in the matrix when the filler particles were coated with polymers. Chiu et al. [56] modified aluminum nitride with polysilazane and amorphous silicon oxycarbide ceramic to obtain significant increase in thermal conductivity compared to untreated filler.

Filler treatment also increases lifetime and morphology stability of the final composite and protects the filler from attack by water [55]. Some researchers have found that filler surface 
treatment leads to increase in density due to reduction in free volume within the composites[57]. Covalent surface modification can decrease thermal conductivity of the filler itself, but the tradeoff in enhanced load transfer yields large improvements to mechanical properties [52]. Acid treatments used for purification or surface treatment may also reduce the aspect ratio which could increase percolation threshold.

\subsection{Filler volume fraction}

While increasing filler loading enhances thermal conductivity, higher loading can also cause mechanical instability and processing challenges by interfering with the shear rateviscosity relationship. Filler agglomerates may also form [29], increasing the effective filler size. The effects of filler agglomeration are not well understood; they may serve as mechanical defects

or crack initiation sites, but in some cases, they improve thermal conductivity [57,58]. Most well-dispersed fillers improve mechanical properties such as modulus and stiffness while enhancing the thermal conductivity [41]. Generally, percolation theory provides a framework for understanding the effects of loading on energy transfer within composites. The relationship between thermal conductivity, percolation threshold and volume fraction can be characterized by a scaling law [59],

$$
K^{*} \propto K\left(f-f_{c}\right)^{t}
$$

Where

$K^{*}$ is the thermal conductivity of composite, $K$ is the thermal conductivity of filler, $f$ is the filler volume fraction, $f_{c}$ is the percolation threshold, and $t$ is the percolation exponent (varies according to the system). 
Some results contradicting percolation theory have also been obtained, where thermal conductivity values obtained beyond the percolation threshold were lower than the thermal conductivity before reaching the percolation threshold. This could be attributed to the formation of huge number of interfaces and imperfections in the polymer matrix.

\subsection{Filler aspect ratio}

High aspect ratio favors conductive network formation at lower volume fractions due to a lower percolation threshold $[57,60,61]$. When aspect ratio increases, the probability that two adjacent particles are close enough for phonon transport increases, resulting in lower critical volume fraction [62]. It is desirable to incorporate the smallest volume fraction of filler possible, to keep the composite density low and also to reduce the number of "dead-ends" or areas for increased phonon scattering. Ideally, all added filler participates in the percolated network. Larger particles form thicker conductive paths at high filler concentration. Using fillers with smaller sizes will result in a lower percolation threshold and formation of conductive pathways at lower loading [63-65][29]. Filler dimensionality also influences thermal conductivity; fibers are better than flakes and flakes are better than spheres [58,63]. Tekce et al. [66] studied the effect of particle shape on thermal conductivity in copper reinforced polyamide composites and found that the thermal conductivity after incorporating $30 \mathrm{vol} \%$ copper fibers was $8.71 \mathrm{~W} / \mathrm{mK}$ and that by using $60 \mathrm{vol} \%$ spherical copper fillers was $3.66 \mathrm{~W} / \mathrm{mK}$, a more than $200 \%$ increase with only $50 \%$ of the filler content. Polydisperse fillers result in higher packing and better formation of conductive pathways, hence hybrid systems containing fillers of various shapes, size and type offer better thermal conductivity [60]. Lee et al. [67] studied incorporating aluminum nitride, silicon carbide and boron nitride in a hybrid system with high density polyethylene matrix. They 
found a rapid increase in thermal conductivity at filler volume fraction between 50 and 60 vol\%. They obtained better results by using a treated, hybrid filler system with increased thermal conductivity and reduced thermal expansion. Zhou et al. [68] studied graphite flakes in polyvinyl butyral binder with various added carbonaceous fillers. It was found that carbon black particles could form gaps between graphite flakes, reducing thermal conductivity, depicted in Figure 5. Carbon nanotubes were able to bridge graphite flakes to enhance percolation.

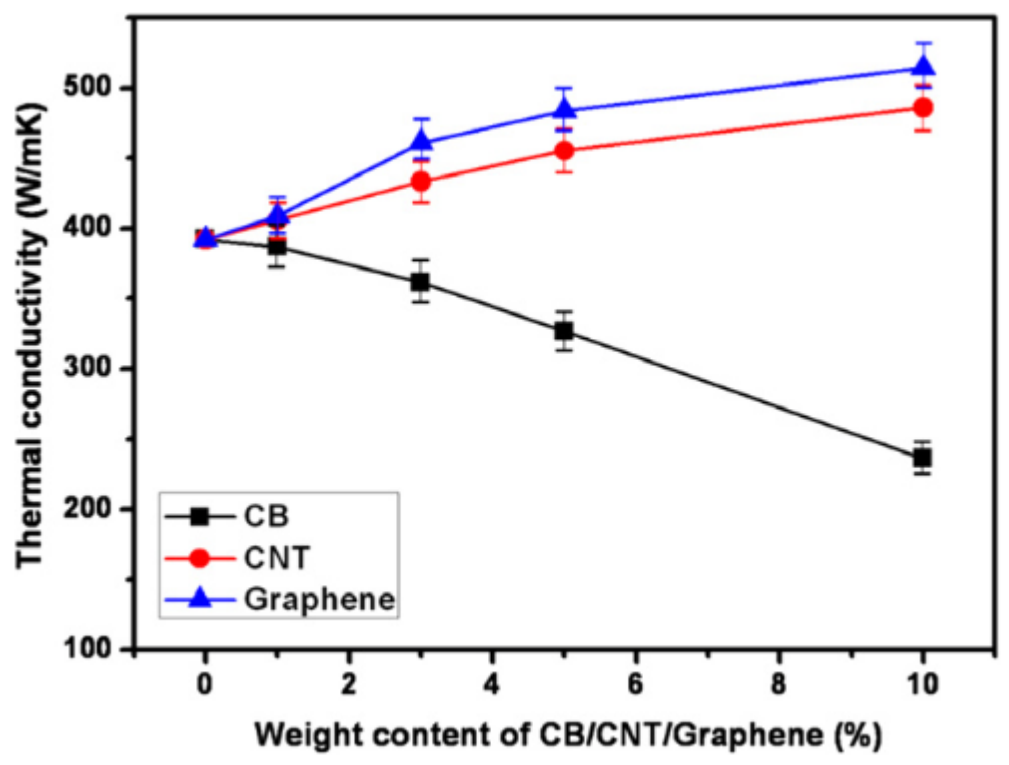

Figure 5. Thermal conductivity of PVB-CB/CNT/graphene composites [68]

In addition to all the above mentioned filler properties, specific interactions between filler and the polymer matrix can also influence thermal conductivity [69].

\subsection{Filler alignment}


Achieving dispersion and proper alignment in composites is not trivial, and the morphology can change with each additional processing step. Alignment of fillers exhibits disparate effects on thermal conductivity of composites. During processing of composites, anisotropic fillers typically align along the flow direction, enhancing the thermal conductivity and mechanical properties of the composite parallel to the flow direction [70]. However, the alignment effect is less predictable for fractal or higher dimension fillers. Kim et al. [71] reported significant improvements in elastic modulus, electrical and thermal conductivities (from 0.28 $\mathrm{W} / \mathrm{mK}$ to $0.70 \mathrm{~W} / \mathrm{mK}$ ), by aligning $5 \mathrm{wt} \%$ carbon nanotubes in ethylene propylene diene rubber. Huang et al. [72] reported increase in thermal conductivity at $0.4 \%$ of filler loading by using aligned carbon nanotubes in silicone elastomer. Isotropic fillers show similar $\mathrm{K}$ values in all directions, but anisotropic fillers exhibit lower $\mathrm{K}$ in the transverse direction compared to the axis parallel to the filler $[29,42,73,74]$. When the fillers are isotropic, contacts between the filler particles form bridges, leading to increased thermal conductivity. A close packed structure is necessary to maximize the network for heat conduction inside the polymer matrix [67]. Ghose et al. [75] measured thermal conductivity along the flow direction and perpendicular to the flow direction in ethyl vinyl acetate/metallized multi-wall carbon nanotube (Nickel, Silver, Copper and Aluminum) composites. . Silver, copper and nickel-carbon nanotube composites, showed $50 \%, 67 \%$ and $200 \%$ improvement respectively, compared to the neat thermoplastic resin. Multiwall carbon nanotube samples at 30\% loading exhibited a thermal conductivity of 0.469 in the perpendicularly aligned fillers, $2.942 \mathrm{~W} / \mathrm{mK}$ along the direction of alignment of fillers and $0.705 \mathrm{~W} / \mathrm{mK}$ in case of un-oriented samples. In general, thermal conductivity is higher in directions parallel to orientation of fillers than in directions perpendicular to filler orientation. 


\section{CHALLENGES IN PROCESSING HIGHLY FILLED THERMALLY CONDUCTIVE COMPOSITES}

During processing, thermoplastics subjected to high temperatures combined with shear mixing and prolonged residence time undergo thermal and mechanical stress and eventually molecular weight degradation from chain scission. The highly non-equilibrium conditions during compounding, extrusion and injection molding lead to extreme temperature, pressure and shear gradients that can significantly affect the final structure within thermoplastic parts. High filler loading poses substantial processing challenges because of increased viscosity as particle jamming becomes dominant. The method used to process filled thermoplastics affects the conductivity since processing affects both dispersion and alignment. A summary of the relevant findings regarding processing is given below.

\subsection{Effect of Temperature and Thermal Conductivity}

Processing conditions such as mold temperature, melt temperature and injection velocity influence filler orientation, dispersion and interparticle distance, degree of crystallinity and aspect ratio of conductive fillers. The required mold temperature and inherent thermal conductivity of the resin complicate the molding process. Since the filled thermoplastics transfer heat at a much higher rate compared to conventional thermoplastics, they freeze off in the mold before filling the entire cavity, leading to incomplete fill and reduced degree of crystallinity [76]. Weidenfeller et al. [77] studied the cooling behavior during injection molding and observed that copper filled polypropylene cooled fastest due to high thermal conductivity. Parts can be processed at high melt temperatures and low injection speeds to obtain uniform conductivities throughout the parts; however, low injection velocities often result in incomplete fill as the thermoplastic melt solidifies halfway through. High mold temperature can alleviate the freeze off 
effect, but the part must be cooled sufficiently for ejection as well. Degree of crystallinity determines the mechanical properties and can also interfere with the cooling behavior. Some studies have found that degree of crystallinity is proportional to the cooling rate as thermally conductive fillers present in the thermoplastic resin behave as a nucleating agent, increasing the number and decreasing the size of crystals. Suplicz et al. [76] found that 30 vol\% of titanium dioxide, talc and boron nitride decreased the cooling time to reach ejection temperature by $35 \%$, $50 \%$ and $70 \%$ respectively. They also found that above $10 \mathrm{vol} \%$ of boron nitride in the polymer results in faster cooling, reducing the crystallinity which affects the properties of the part; this happened in spite of filler serving as a nucleating agent.

\subsection{Effect of Viscosity}

In injection molding, viscosity of the thermoplastic resin should be low enough so that it can flow throughout the cavity with moderate pressure and no excessive shear heating to cause degradation. This is an especially important requirement for thin-walled parts due to the inverse relationship between wall thickness and pressure drop. Highly loaded composites exhibit high viscosity and yield stress, which causes the melt to flow poorly and creates melt fracture or disruption. Serious defects such as short shot and unfilled corners result during injection molding. Thermoplastic resins with ceramic based and carbon based fillers must be processed at higher temperatures compared to the neat resin, which can degrade the matrix leading to parts with damage and inferior properties. Also, high shear rates during injection molding can rupture the filler particles and damage the conductive network.

Ngyuen et al. [78] studied the flow behavior, morphology and mechanical properties of injection molded parts. They found that filling thicker cavities was easier than filling thinner cavities, increasing the mold or melt temperature increased the flow length linearly, and 
temperature had less influence on flow length than the flow rate. It was also observed that particles were aligned in the flow direction closest to the gate section and perpendicular to the flow direction far from the gate, in the shear layer. These alignment effects are well known for filled polymers in injection molding more generally, but the resulting anisotropy may be more detrimental when high thermal conductivity is required.

\subsection{Effect of Dispersion}

Dispersion is critical since it helps to form uniform paths for thermal transport, so the method of mixing is important; there must be a viable method to disperse any additive designed to enhance thermal conductivity (or any other property of interest). Melt mixing is compatible with industrial scale processing [13]. Hong et al. [79] achieved aspect ratio 1.7 times greater by using master batches of multiwall carbon nanotubes in Poly(dimethyl siloxane) matrix. Composites carboxylated MWCNT masterbatches showed improved dispersion over untreated MWCNT composites, resulting in $10 \%$ higher thermal conductivity. Shearing of the filler system can possibly reduce the length of the fillers, thereby reducing the aspect ratio. Agari et al. [80] investigated dispersion of graphite in polyethylene using four methods: powder mixing, solution mixing, roll-mill mixing and melt mixing and found the thermal conductivity improved in that order. Ultrasonication can reduce aggregation of fillers [50], however, it is not considered suitable for scale-up in manufacturing.

\subsection{Novel Techniques to Overcome Challenges}

To maintain short molding cycles, mold temperature should be lower than the freezing temperature of the thermoplastic melt. This is particularly problematic when the melt is highly thermally conductive. A frozen layer is formed at the mold wall which causes melt fracture and disruption leading to poor quality parts and loss of properties. This will also aggravate weld 
lines, flow lines, jetting, short shot and floating fiber phenomena. Higher mold temperature is required to enhance product quality and lower mold temperature is required to shorten the molding cycle. New techniques are available to rapidly cool and heat the mold alternately during the injection molding cycle [81-84]. Two modes are available to achieve cyclic mold temperature: exterior mold heating and interior mold heating. Exterior methods include flame heating, induction heating, infrared heating and surface heating based on the mold structure and final parts needed. In exterior heating, the heat generated is directed mainly toward the surface of the mold cavity. The temperature of the mold cavity is raised very rapidly and efficiently since only a part of the metal volume has to be heated. However, there can be uneven temperature distribution of the cavity surface and safety issues. An alternative method is to coat a thin layer of relatively lower thermally conductive material on the mold surface to reduce the rate at which heat is carried away after fill. For interior heating methods, electric cartridge heaters are used, but efficiency is lower and energy consumption much higher since the whole mold must be heated rather than only the surface. Induction heating helps to obtain a resin-rich surface of the

final parts and prevent surface defects or other flow issues. These techniques can temporarily achieve very high mold temperature, which enables processing of a large range of materials and reduces the cycle time and energy consumption.

\section{CONCLUSION}

Polymers have become attractive materials for many applications due to their light weight, cost and strength-to-weight ratio. Polymer properties are highly tailorable through the incorporation of different fillers to yield both thermally and electrically conducting composites. Each type of filler has its own advantages and disadvantages; therefore, hybrid systems tend to 
impart synergistic effects to the end product. A number of factors influence the nature of the resulting composites at different circumstances: (1) filler surface treatment, (2) filler volume fraction, (3) filler aspect ratio, (4) filler orientation, (5) chemical structure of the base polymer, (6) temperature, (7) viscosity, and (8) dispersion and distribution of filler in base polymer. Functionalization often improves dispersion and transport at the interface; however, beyond a certain limit it could damage the filler surface. The higher the amount of filler, the better the heat transfer. On the other hand, high filler content will interfere with viscosity, processing, and mechanical stability and hence affect product performance. Filler size and shape play a major role in determining percolation threshold in a composite, and orientation and dispersion of filler are also critical. Control over the major parameters will result in polymers with good thermal conductivity without any major difficulties during processing. However, significant research is still required to draw solid conclusions about the behavior of different kinds of polymers as well as fillers and how their characteristics affect thermal conductivity. Although the benefits could be tremendous, it is likely that radical redesign of heat exchanger components will be required to enable the use of thermoplastic composites in this application.

\section{Acknowledgement}

The information, data, or work presented herein was funded in part by the Office of Energy Efficiency and Renewable Energy (EERE), U.S. Department of Energy, under Award Number DE-EE0005775.

\section{Disclaimer}

The information, data, or work presented herein was funded in part by an agency of the United States Government. Neither the United States Government nor any agency thereof, nor any of 
their employees, makes any warranty, express or implied, or assumes any legal liability or responsibility for the accuracy, completeness, or usefulness of any information, apparatus, product, or process disclosed, or represents that its use would not infringe privately owned rights. Reference herein to any specific commercial product, process, or service by trade name, trademark, manufacturer, or otherwise does not necessarily constitute or imply its endorsement, recommendation, or favoring by the United States Government or any agency thereof. The views and opinions of authors expressed herein do not necessarily state or reflect those of the United States Government or any agency thereof.

\section{REFERENCE}

[1] P. Rodriguez, Selection of Materials for Heat Exchangers, (1997).

[2] D.E. Kline, Thermal conductivity studies of polymers, J. Polym. Sci. 50 (1961) 441-450. doi:10.1002/pol.1961.1205015413.

[3] W.N. Dos Santos, J. a. De Sousa, R. Gregorio, Thermal conductivity behaviour of polymers around glass transition and crystalline melting temperatures, Polym. Test. 32 (2013) 987-994. doi:10.1016/j.polymertesting.2013.05.007.

[4] D.R. Anderson, Thermal Conductivity of Polymers, Chem. Rev. 66 (1966) 677690. doi:10.1021/cr60244a004.

[5] C.L. Choy, Thermal conductivity of polymers, Polymer. 18 (1977) 984-1004. doi:10.1016/0032-3861(77)90002-7.

[6] Y. Xu, D.D.L. Chung, C. Mroz, Thermally conducting aluminum nitride polymermatrix composites, Compos. - Part Appl. Sci. Manuf. 32 (2001) 1749-1757. doi:10.1016/S1359-835X(01)00023-9.

[7] G.-H. Kim, D. Lee, A. Shanker, L. Shao, M.S. Kwon, D. Gidley, J. Kim, K.P. Pipe, High thermal conductivity in amorphous polymer blends by engineered interchain interactions, Nat. Mater. 14 (2014) 295-300. doi:10.1038/nmat4141.

[8] X. Wang, V. Ho, R. a. Segalman, D.G. Cahill, Thermal Conductivity of HighModulus Polymer Fibers : Supplemental Materials, Macromolecules. 46 (2013) 4937-4943.

[9] S. Shen, A. Henry, J. Tong, R. Zheng, G. Chen, Polyethylene nanofibres with very high thermal conductivities., Nat. Nanotechnol. 5 (2010) 251-255. doi:10.1038/nnano.2010.27.

[10] S.M. Lebedev, O.S. Gefle, Evaluation of electric, morphological and thermal properties of thermally conductive polymer composites, Appl. Therm. Eng. 91 (2015) 875-882. doi:10.1016/j.applthermaleng.2015.08.046. 
[11] Y.K. Shin, W.S. Lee, M.J. Yoo, E.S. Kim, Effect of BN filler on thermal properties of HDPE matrix composites, Ceram. Int. 39 (2013) S569-S573. doi:10.1016/j.ceramint.2012.10.137.

[12] R. Kochetov, A.V. Korobko, T. Andritsch, P.H.F. Morshuis, S.J. Picken, J.J. Smit, Modelling of the thermal conductivity in polymer nanocomposites and the impact of the interface between filler and matrix, J. Phys. Appl. Phys. 44 (2011) 395401. doi:10.1088/0022-3727/44/39/395401.

[13] W.S. Khan, R. Asmatulu, I. Ahmed, T.S. Ravigururajan, Thermal conductivities of electrospun PAN and PVP nanocomposite fibers incorporated with MWCNTs and NiZn ferrite nanoparticles, Int. J. Therm. Sci. 71 (2013) 74-79. doi:10.1016/j.ijthermalsci.2013.03.006.

[14] A. Agrawal, A. Satapathy, International Journal of Thermal Sciences Mathematical model for evaluating effective thermal conductivity of polymer composites with hybrid fi llers, Int. J. Therm. Sci. 89 (2015) 203-209. doi:10.1016/j.ijthermalsci.2014.11.006.

[15] H.J.H. Brouwers, C.W.M. Van Der Geld, Heat transfer, condensation and fog formation in crossflow plastic heat exchangers, Int. J. Heat Mass Transf. 39 (1996) 391-405. doi:10.1016/0017-9310(95)00113-N.

[16] L. Chen, Z. Li, Z.Y. Guo, Experimental investigation of plastic finned-tube heat exchangers, with emphasis on material thermal conductivity, Exp. Therm. Fluid Sci. 33 (2009) 922-928. doi:10.1016/j.expthermflusci.2009.04.001.

[17] R.A.F. Cabral, J.A.W. Gut, V.R.N. Telis, J. Telis-Romero, Non-newtonian flow and pressure drop of pineapple juice in a plate heat exchanger, Braz. J. Chem. Eng. 27 (2010) 563-571. doi:10.1590/S0104-66322010000400008.

[18] a. B. Patel, J.G. Brisson, Design, construction, and performance of plastic heat exchangers for sub-Kelvin use, Cryogenics. 40 (2000) 91-98. doi:10.1016/S0011-2275(00)00006-0.

[19] V.H. Morcos, H.M. Shafey, Performance analysis of a plastics shell-and-tube heat exchanger, J. Elastomers Plast. 27 (1995) 200-213. doi:10.1177/009524439502700208.

[20] W. Liu, J. Davidson, S. Mantell, Thermal Analysis of Polymer Heat Exchangers for Solar Water Heating: A Case Study, J. Sol. Energy Eng. 122 (2000) 84. doi:10.1115/1.1288027.

[21] S.I. Kundalwal, R. Suresh Kumar, M.C. Ray, Effective thermal conductivities of a novel fuzzy carbon fiber heat exchanger containing wavy carbon nanotubes, Int. J. Heat Mass Transf. 72 (2014) 440-451. doi:10.1016/j.ijheatmasstransfer.2014.01.025.

[22] Y. Qin, B. Li, S. Wang, Experimental Investigation of a Novel Polymeric Heat Exchanger Using Modified Polypropylene Hollow Fibers, Ind. Eng. Chem. Res. 51 (2012) 882-890. doi:10.1021/ie202075a.

[23] X. Yan, B. Li, B. Liu, J. Zhao, Y. Wang, H. Li, Analysis of improved novel hollow fiber heat exchanger, Appl. Therm. Eng. 67 (2014) 114-121. doi:10.1016/j.applthermaleng.2014.03.021.

[24] S. Agarwal, R. Gupta, Thermal Conductivity of Polymer Nanocomposites, in: Polym. Nanocomposites Handb., CRC Press, 2009. doi:doi:10.1201/9781420009804-c17. 
[25] F.R. Schilling, Thermal conductivity, thermal diffusivity, and specific heat capacity of particle filled polypropylene, 35 (2004) 423-429. doi:10.1016/j.compositesa.2003.11.005.

[26] Y. Agari, A. Ueda, S. Nagai, Thermal conductivity of a polymer composite, J. Appl. Polym. Sci. 49 (1993) 1625-1634. doi:10.1002/app.1993.070490914.

[27] Y.P. Mamunya, V. V. Davydenko, P. Pissis, E. V. Lebedev, Electrical and thermal conductivity of polymers filled with metal powders, Eur. Polym. J. 38 (2002) 1887-1897. doi:10.1016/S0014-3057(02)00064-2.

[28] a. Boudenne, L. Ibos, M. Fois, J.C. Majesté, E. Géhin, Electrical and thermal behavior of polypropylene filled with copper particles, Compos. Part Appl. Sci. Manuf. 36 (2005) 1545-1554. doi:10.1016/j.compositesa.2005.02.005.

[29] Z. Han, A. Fina, Thermal conductivity of carbon nanotubes and their polymer nanocomposites: A review, Prog. Polym. Sci. Oxf. 36 (2011) 914-944. doi:10.1016/j.progpolymsci.2010.11.004.

[30] D.D.. Chung, Materials for thermal conduction, Appl. Therm. Eng. 21 (2001) 1593-1605. doi:10.1016/S1359-4311(01)00042-4.

[31] I. Krupa, V. Cecen, A. Boudenne, J. Prokeš, I. Novák, The mechanical and adhesive properties of electrically and thermally conductive polymeric composites based on high density polyethylene filled with nickel powder, Mater. Des. 51 (2013) 620-628. doi:10.1016/j.matdes.2013.03.067.

[32] M. Rusu, N. Sofian, D. Rusu, Mechanical and thermal properties of zinc powder filled high density polyethylene composites, Polym. Test. 20 (2001) 409-417. doi:10.1016/S0142-9418(00)00051-9.

[33] A.S. Luyt, J.A. Molefi, H. Krump, Thermal, mechanical and electrical properties of copper powder filled low-density and linear low-density polyethylene composites, Polym. Degrad. Stab. 91 (2006) 1629-1636. doi:10.1016/j.polymdegradstab.2005.09.014.

[34] S. Chin, Recent progress in the development and properties of novel metal matrix nanocomposites reinforced with carbon nanotubes and graphene nanosheets, Mater. Sci. Eng. R. 74 (2013) 281-350. doi:10.1016/j.mser.2013.08.001.

[35] B.L.M. Veca, M.J. Meziani, W. Wang, X. Wang, F. Lu, P. Zhang, Y. Lin, R. Fee, J.W. Connell, Y. Sun, Carbon Nanosheets for Polymeric Nanocomposites with High Thermal Conductivity, (2009) 2088-2092. doi:10.1002/adma.200802317.

[36] A.A. Balandin, S. Ghosh, W. Bao, I. Calizo, D. Teweldebrhan, F. Miao, C.N. Lau, Superior Thermal Conductivity of Single-Layer Graphene 2008, (2008).

[37] K. Pielichowska, K. Pielichowski, Phase change materials for thermal energy storage, Prog. Mater. Sci. 65 (2014) 67-123. doi:10.1016/j.pmatsci.2014.03.005.

[38] Q. Zheng, Z. Li, J. Yang, J. Kim, Progress in Materials Science Graphene oxidebased transparent conductive films, Prog. Mater. Sci. 64 (2014) 200-247. doi:10.1016/j.pmatsci.2014.03.004.

[39] V. Singh, D. Joung, L. Zhai, S. Das, Progress in Materials Science Graphene based materials : Past, present and future, Prog. Mater. Sci. 56 (2011) 1178-1271. doi:10.1016/j.pmatsci.2011.03.003. 
[40] Y. Chen, J. Ting, Ultra high thermal conductivity polymer composites, 40 (2002) 359-362.

[41] S.M. Ha, H.L. Lee, S.-G. Lee, B.G. Kim, Y.S. Kim, J.C. Won, W.J. Choi, D.C. Lee, J. Kim, Y. Yoo, Thermal conductivity of graphite filled liquid crystal polymer composites and theoretical predictions, Compos. Sci. Technol. 88 (2013) 113119. doi:10.1016/j.compscitech.2013.08.022.

[42] S.M. Ha, H.L. Lee, S.-G. Lee, B.G. Kim, Y.S. Kim, J.C. Won, W.J. Choi, D.C. Lee, J. Kim, Y. Yoo, Thermal conductivity of graphite filled liquid crystal polymer composites and theoretical predictions, Compos. Sci. Technol. 88 (2013) 113119. doi:10.1016/j.compscitech.2013.08.022.

[43] S.N. Leung, M.O. Khan, E. Chan, H. Naguib, F. Dawson, V. Adinkrah, L. LakatosHayward, Analytical modeling and characterization of heat transfer in thermally conductive polymer composites filled with spherical particulates, Compos. Part B Eng. 45 (2013) 43-49. doi:10.1016/j.compositesb.2012.10.001.

[44] Y. Xu, D.D.L. Chung, C. Mroz, Thermally conducting aluminum nitride polymermatrix composites, Compos. - Part Appl. Sci. Manuf. 32 (2001) 1749-1757. doi:10.1016/S1359-835X(01)00023-9.

[45] H. Ishida, S. Rimdusit, Very high thermal conductivity obtained by boron nitride-filled polybenzoxazine, Thermochim. Acta. 320 (1998) 177-186. doi:10.1016/S0040-6031(98)00463-8.

[46] S. Yu, P. Hing, X. Hu, Thermal conductivity of polystyrene \pm aluminum nitride composite, 33 (2002) 289-292.

[47] S. Yeol, H. Min, S.Y. Kim, J.R. Youn, Synergistic improvement of thermal conductivity of thermoplastic composites with mixed boron nitride and multiwalled carbon nanotube fillers, Carbon. 50 (2012) 4830-4838. doi:10.1016/j.carbon.2012.06.009.

[48] B.L. Zhu, J. Wang, H. Zheng, J. Ma, J. Wu, R. Wu, Composites : Part B Investigation of thermal conductivity and dielectric properties of LDPE-matrix composites filled with hybrid filler of hollow glass microspheres and nitride particles, 69 (2015) 496-506. doi:10.1016/j.compositesb.2014.10.035.

[49] J.Z. Liang, Estimation of thermal conductivity for polypropylene/hollow glass bead composites, Compos. Part B Eng. 56 (2014) 431-434. doi:10.1016/j.compositesb.2013.08.072.

[50] J.P. Cao, J. Zhao, X. Zhao, F. You, H. Yu, G.H. Hu, Z.M. Dang, High thermal conductivity and high electrical resistivity of poly(vinylidene fluoride)/polystyrene blends by controlling the localization of hybrid fillers, Compos. Sci. Technol. 89 (2013) 142-148. doi:10.1016/j.compscitech.2013.09.024.

[51] M. Li, Y. Wan, Z. Gao, G. Xiong, X. Wang, C. Wan, H. Luo, Preparation and properties of polyamide 6 thermal conductive composites reinforced with fibers, Mater. Des. 51 (2013) 257-261. doi:10.1016/j.matdes.2013.03.076.

[52] H.-S. Kim, Y.S. Chae, B.H. Park, J.-S. Yoon, M. Kang, H.-J. Jin, Thermal and electrical conductivity of poly(l-lactide)/multiwalled carbon nanotube nanocomposites, Curr. Appl. Phys. 8 (2008) 803-806. doi:10.1016/j.cap.2007.04.032. 
[53] K. Ahn, K. Kim, M. Kim, J. Kim, Fabrication of silicon carbonitride-covered boron nitride / Nylon 6,6 composite for enhanced thermal conductivity by melt process, Ceram. Int. 41 (2015) 2187-2195. doi:10.1016/j.ceramint.2014.10.018.

[54] D.S. Muratov, D.V. Kuznetsov, I. a. Il'inykh, I.N. Burmistrov, I.N. Mazov, Thermal conductivity of polypropylene composites filled with silane-modified hexagonal BN, Compos. Sci. Technol. 111 (2015) 40-43. doi:10.1016/j.compscitech.2015.03.003.

[55] G.W. Lee, M. Park, J. Kim, J.I. Lee, H.G. Yoon, Enhanced thermal conductivity of polymer composites filled with hybrid filler, Compos. Part Appl. Sci. Manuf. 37 (2006) 727-734. doi:10.1016/j.compositesa.2005.07.006.

[56] H.T. Chiu, T. Sukachonmakul, M.T. Kuo, Y.H. Wang, K. Wattanakul, Surface modification of aluminum nitride by polysilazane and its polymer-derived amorphous silicon oxycarbide ceramic for the enhancement of thermal conductivity in silicone rubber composite, Appl. Surf. Sci. 292 (2014) 928-936. doi:10.1016/j.apsusc.2013.12.081.

[57] I. a. Tsekmes, R. Kochetov, P.H.F. Morshuis, J.J. Smit, Thermal conductivity of polymeric composites: A review, 2013 IEEE Int. Conf. Solid Dielectr. ICSD. (2013) 678-681. doi:10.1109/ICSD.2013.6619698.

[58] E. Kandare, A.A. Khatibi, S. Yoo, R. Wang, J. Ma, P. Olivier, N. Gleizes, C.H. Wang, Composites : Part A Improving the through-thickness thermal and electrical conductivity of carbon fibre / epoxy laminates by exploiting synergy between graphene and silver nano-inclusions, Compos. PART A. 69 (2015) 72-82. doi:10.1016/j.compositesa.2014.10.024.

[59] Y. Zhu, K. Chen, F. Kang, Percolation transition in thermal conductivity of $\beta$ Si3N4 filledepoxy, Solid State Commun. 158 (2013) 46-50. doi:10.1016/j.ssc.2013.01.013.

[60] K. Sanada, Y. Tada, Y. Shindo, Thermal conductivity of polymer composites with close-packed structure of nano and micro fillers, Compos. Part Appl. Sci. Manuf. 40 (2009) 724-730. doi:10.1016/j.compositesa.2009.02.024.

[61] M.J. Sobkowicz, E.A. White, J.R. Dorgan, Supramolecular bionanocomposites 3: Effects of surface functionality on electrical and mechanical percolation, J. Appl. Polym. Sci. 122 (2011) 2563-2572.

[62] G. Droval, J. Feller, P. Salagnac, P. Glouannec, Thermal conductivity enhancement of electrically insulating syndiotactic poly ( styrene ) matrix for diphasic conductive polymer composites y, (2006) 732-745. doi:10.1002/pat.

[63] C. T'Joen, Y. Park, Q. Wang, a. Sommers, X. Han, a. Jacobi, A review on polymer heat exchangers for HVAC\&R applications, Int. J. Refrig. 32 (2009) 763-779. doi:10.1016/j.ijrefrig.2008.11.008.

[64] J.P. Hong, S.W. Yoon, T. Hwang, J.S. Oh, S.C. Hong, Y. Lee, J. Do Nam, High thermal conductivity epoxy composites with bimodal distribution of aluminum nitride and boron nitride fillers, Thermochim. Acta. 537 (2012) 70-75. doi:10.1016/j.tca.2012.03.002.

[65] D.M. Bigg, Thermally conductive polymer compositions, Polym. Compos. 7 (1986) 125-140. doi:10.1002/pc.750070302. 
[66] H.S. Tekce, D. Kumlutas, I.H. Tavman, Effect of Particle Shape on Thermal Conductivity of Copper Reinforced Polymer Composites, J. Reinf. Plast. Compos. 26 (2007) 113-121. doi:10.1177/0731684407072522.

[67] G.W. Lee, M. Park, J. Kim, J.I. Lee, H.G. Yoon, Enhanced thermal conductivity of polymer composites filled with hybrid filler, Compos. Part Appl. Sci. Manuf. 37 (2006) 727-734. doi:10.1016/j.compositesa.2005.07.006.

[68] S. Zhou, J. Xu, Q.H. Yang, S. Chiang, B. Li, H. Du, C. Xu, F. Kang, Experiments and modeling of thermal conductivity of flake graphite/polymer composites affected by adding carbon-based nano-fillers, Carbon. 57 (2013) 452-459. doi:10.1016/j.carbon.2013.02.018.

[69] I. Krupa, I. Chod, Physical properties of thermoplastic / graphite composites, 37 (2001) 2159-2168.

[70] H.F. and M.I. and T.K. and A. Yamanaka, Thermal Conductivity and Diffusivity of High-Strength Polymer Fibers, Jpn. J. Appl. Phys. 36 (1997) 5633.

[71] Y.A. Kim, T. Hayashi, M. Endo, Y. Gotoh, N. Wada, J. Seiyama, Fabrication of aligned carbon nanotube-filled rubber composite, Scr. Mater. 54 (2006) 31-35. doi:10.1016/j.scriptamat.2005.09.014.

[72] H. Huang, C.H. Liu, Y. Wu, S. Fan, Aligned Carbon Nanotube Composite Films for Thermal Management, Adv. Mater. 17 (2005) 1652-1656. doi:10.1002/adma.200500467.

[73] J.-H. Hong, D.-W. Park, S.-E. Shim, A Review on Thermal Conductivity of Polymer Composites Using Carbon-Based Fillers : Carbon Nanotubes and Carbon Fibers, Carbon Lett. 11 (2010) 347-356. doi:10.5714/CL.2010.11.4.347.

[74] K. Ahn, K. Kim, M. Kim, J. Kim, Fabrication of silicon carbonitride-covered boron nitride / Nylon 6, 6 composite for enhanced thermal conductivity by melt process, Ceram. Int. 41 (2015) 2187-2195. doi:10.1016/j.ceramint.2014.10.018.

[75] S. Ghose, K. a. Watson, D.C. Working, J.W. Connell, J.G. Smith, Y.P. Sun, Thermal conductivity of ethylene vinyl acetate copolymer/nanofiller blends, Compos. Sci. Technol. 68 (2008) 1843-1853. doi:10.1016/j.compscitech.2008.01.016.

[76] A. Suplicz, F. Szabo, J.G. Kovacs, Injection molding of ceramic filled polypropylene: The effect of thermal conductivity and cooling rate on crystallinity, Thermochim. Acta. 574 (2013) 145-150. doi:10.1016/j.tca.2013.10.005.

[77] F.R. Schilling, B. Weidenfeller, M. Ho, Cooling behaviour of particle filled polypropylene during injection moulding process, 36 (2005) 345-351. doi:10.1016/j.compositesa.2004.07.002.

[78] T.N. Nguyen, K. Geicer, T. Walther, on Morphology and Mechanical Properties of Injection Molded Parts, Polym. Eng. Sci. 40 (2000) 1643-1654.

[79] J. Hong, J. Lee, C.K. Hong, S.E. Shim, Effect of dispersion state of carbon nanotube on the thermal conductivity of poly(dimethyl siloxane) composites, Curr. Appl. Phys. 10 (2010) 359-363. doi:10.1016/j.cap.2009.06.028.

[80] Y. Agari, A. Ueda, S. Nagai, Thermal conductivities of composites in several types of dispersion systems, J. Appl. Polym. Sci. 42 (1991) 1665-1669. doi:10.1002/app.1991.070420621. 
[81] W. Guilong, Z. Guoqun, L. Huiping, G. Yanjin, Analysis of thermal cycling efficiency and optimal design of heating/cooling systems for rapid heat cycle injection molding process, Mater. Des. 31 (2010) 3426-3441. doi:10.1016/j.matdes.2010.01.042.

[82] C.-L. Xiao, H.-X. Huang, X. Yang, Development and application of rapid thermal cycling molding with electric heating for improving surface quality of microcellular injection molded parts, Appl. Therm. Eng. 100 (2016) 478-489. doi:10.1016/j.applthermaleng.2016.02.045.

[83] G. long Wang, G. qun Zhao, X. xin Wang, Heating/cooling channels design for an automotive interior part and its evaluation in rapid heat cycle molding, Mater. Des. 59 (2014) 310-322. doi:10.1016/j.matdes.2014.02.047.

[84] G. Wang, G. Zhao, X. Wang, Development and evaluation of a new rapid mold heating and cooling method for rapid heat cycle molding, Int. J. Heat Mass Transf. 78 (2014) 99-111. doi:10.1016/j.ijheatmasstransfer.2014.06.062. 